\title{
Professional Master's degree in Nursing: knowledge production and challenges
}

\author{
Denize Bouttelet Munari ${ }^{1}$ \\ Cristina Maria Garcia de Lima Parada ${ }^{2}$ \\ Francine de Lima Gelbcke ${ }^{3}$ \\ Zenith Rosa Silvino ${ }^{4}$ \\ Luana Cássia Miranda Ribeiro ${ }^{5}$ \\ Carmen Gracinda Silvan Scochi ${ }^{6}$
}

Objective: to analyze the production of knowledge resulting from the professional master's degree programs in Nursing and to reflect about their perspectives for the area. Method: descriptive and analytical study. Data collected from the dissertations of three educational institutions that graduated students in programs of professional master's degree in Nursing between 2006 and 2012 were included. Results: most of the 127 course completion studies analyzed were developed within hospital contexts; there was a focus on the organizational and healthcare areas, in the research fields care process and management, and predominance of qualitative studies. There are various products resulting from the course completion studies: evaluation of services/ healthcare programs and development of processes, care or educational protocols. Conclusion: the programs of professional master's degree in Nursing, which are undergoing a consolidation stage, have recent production under development and there is a gap in the creation of hard technologies and innovation. They are essential for the development of innovative professional practices that articulate the healthcare and educational areas.

Descriptors: Education, Nursing, Graduate; Education, Professional; Scientific Research and Technological Development.

\footnotetext{
${ }^{1}$ PhD, Full Professor, Faculdade de Enfermagem, Universidade Federal de Goiás, Goiânia, Go, Brazil.

2 PhD, Adjunct Professor, Departamento de Enfermagem, Faculdade de Medicina de Botucatu, Universidade Estadual Paulista "Júlio de Mesquita Filho", Botucatu, SP, Brazil.

${ }^{3} \mathrm{PhD}$, Associate Professor, Departamento de Enfermagem, Universidade Federal de Santa Catarina, Florianópolis, SC, Brazil.

${ }^{4} \mathrm{PhD}$, Professor Titular, Escola de Enfermagem Aurora de Afonso Costa, Universidade Federal Fluminense, Niterói, RJ, Brazil.

${ }^{5}$ Doctoral student, Faculdade de Enfermagem, Universidade Federal de Goiás, Goiânia, GO, Brasil.

${ }^{6} \mathrm{PhD}$, Full Professor, Escola de Enfermagem de Ribeirão Preto, Universidade de São Paulo, WHO Collaborating Centre for Nursing Research Development, Ribeirão Preto, SP, Brazil.
}

Corresponding Author: Denize Bouttelet Munari Rua 227, Qd 68 s/n Setor Leste Universitário CEP: 74605-080, Goiânia, GO, Brasil E-mail: denize@fen.ufg.br
Copyright (c) 2014 Revista Latino-Americana de Enfermagem This is an Open Access article distributed under the terms of the Creative Commons Attribution Non-Commercial License (CC BY-NC).

This license lets others distribute, remix, tweak, and build upon your work non-commercially, and although their new works must also acknowledge you and be non-commercial, they don't have to license their derivative works on the same terms. 


\section{Introduction}

The creation of professional master's degrees covered by Opinion number $977 / 65$ of Newton Sucupira(1), which guided the development of the Brazilian postgraduate courses, was already considered a way of qualifying professionals for the workforce. In that opinion, the argument in favor of establishing this level of graduation was based on the need to ensure effective training to technicians and workers to act on the transfer of knowledge.

After 48 years from its proposition and the historical process involving its recognition and regulation in Brazil(2-3), there are still doubts concerning the graduation process in the professional master's degree programs in the various areas of knowledge. Defined as a type of stricto sensu post-graduation, Section 3 of Rule number $17 / 2009^{(3)}$ clarifies that this level of graduation is intended to qualify professionals for the "advanced practice, changing of applied procedures and processes, through the incorporation of the scientific method...". Another highlight is the expectation that the professional develops innovative methods aimed at solving specific problems.

It is showed in the Post-graduation National Plan 2011-2020(4) that these programs should be clear about their particularities and that they "should not be considered, not designed, as a graduation lower than those of academic master's degrees and should be evaluated with help of specific parameters and supported within the grant system".

The graduation process in the professional master's degree programs should be based on the rigor of the development of the stricto sensu post-graduation, with the specific focus on an educational project marked by knowledge and abilities directed at the professional practice and technological progress ${ }^{(5)}$. The result of this process should be what most differentiates it from the academic master's degree, since it allows the formation of professionals outside the academic scenario, who are able to develop and use research to add value to their professional activities having a critical analysis of the work practice and promoting the development and implementation of technological production ${ }^{(6)}$.

For this reason, the evaluation process of the professional master's degree programs has become a strategic issue for the areas of knowledge, taking into account that all of them have developed, within their particularities, evaluation indicators with the differences they require. These indicators are still the subject of debate in many circumstances, including the Higher
Education Technical Scientific Council of the Improvement Coordination of Higher Education Personnel - CTC/CAPES and the National Forum of Professional Master's Degrees. Among other aspects that are reasons for discussion and orientation for the evaluation process are: the origin of entrants, which must be mostly students with professional experience, the monitoring of the programs' graduates and the partnership with the services from which the students come from(7).

For the triennial evaluation 2010-2012, the CAPES determined that specific commissions were established for the evaluation of this level of education and created the Assistance Coordinator of Professional Master's Degree, who will work together with the Area Coordination in the evaluation process, especially seeking their particularities and differences with the academic model.

In the Nursing Area, this process started during the First Forum of Professional Master's Degree in Nursing, which was held in May 2011 in Niteroi, state of Rio de Janeiro, which developed a document sent to the CAPES that, among other aspects, generally indicated the need to make progress in relation to the discussion about specific criteria, as well as the creation of a commission to work towards this perspective. In February 2012, the first group was established by decision of the Area Coordination, when a review of the evaluation form of the professional master's degree, proposed as temporary document(8) and which is being used as basis for the evaluation of the triennium 2010-2012, took place.

Furthermore, for the first time in the Nursing area, in the monitoring seminars held in 2012 and 2013, the coordinators of the professional master's degree had specific forums for discussion, focusing on the particularities, allowing the definition of guidelines so that programs could plan and propose actions to strengthen and achieve their goals.

Taking into account that understanding the professional master's degree in the Nursing area is essential for its consolidation, the present study was undertaken with the purpose of analyzing the production of knowledge resulting from the programs of professional master's degree in Nursing and reflecting about their perspectives in this area.

\section{Method}

This is a descriptive analytical study, with the main purpose of describing and analyzing the characteristics of a certain event or population(9), carried out between May and December 2012. Data collected from the 
dissertations of three educational institutions that graduated students in programs of professional master's degree in Nursing between 2006 and 2012 were included, although there are 14 approved programs in the country. Although the first program in the Nursing area has been conducted by the Universidade Federal de Sao Paulo (UNIFESP), this was not included in this study, since it had a single group and ended its activities in 2004. Thus, the Universidade Federal Fluminense (UFF), which program started in 2004 and graduated its first students in 2006, the Universidade Estadual Paulista "Júlio de Mesquita Filho" (UNESP/Botucatu), which started its activities in 2006 and has graduated students since 2008 and the Universidade Federal de Santa Catarina (UFSC), which selected its first students in 2009 and graduated its first students in 2011, were part of the study. In total, 127 course completion studies were presented in the period studied.

To access the data, the original course completion studies available in the programs' pages were used. Upon access to the dissertations, an instrument specifically developed for this research was used for data collection, which summarized information about the context covered and application of the study, topic area, activity area to which it was linked, objective, methods and generated results/processes, including the classification of the articles published, according to the Qualis Journals of the Nursing field - 2010. For the area/ research field classification, the representation proposal of the Nursing Area in the CAPES, National Council for Scientific and Technological Development - CNPq and Brazilian Nursing Association - $A B E n^{(8,10-11)}$ was used as basis; the classification of research areas was based on a recent national study, also covering the analysis of Nursing post-graduation in Brazil(11).

The analysis and discussion of the results were based on their descriptive and analytical summary, in the light of the CAPES legislation related to professionals master's degree and related national scientific literature. It can be noted that, since the information is public, and as they do not directly involve human beings, there was no need for approval from the Research Ethics Committee, as per the National Health Council's recommendation.

\section{Results}

From the 127 course completion studies used, 81 were from UNESP/Botucatu, 34 from UFF and 12 from UFSC. The annual distribution of this production is shown in Figure 1.

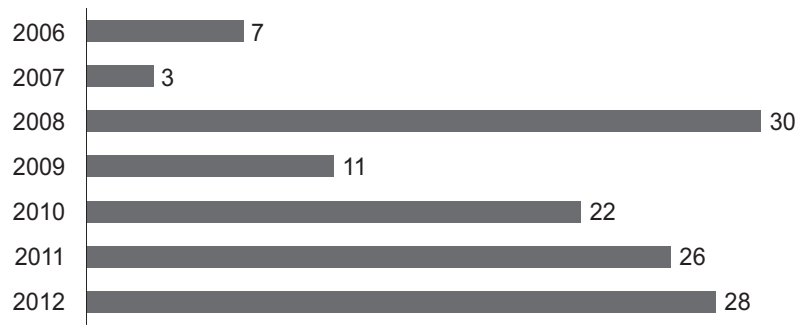

Figure 1 - Distribution of the number (absolute) of course completion studies presented in the programs of professional master's degree in Nursing, Brazil, 2006 to 2012

Regarding the context of development, 81 course completion studies were developed in hospital scenarios, 34 from primary healthcare, 11 from educational institutions and one from the industry.

When the course completion studies are evaluated according to the area/field and research areas, there is a trend of concentration in the organizational (66/52.0\%) and healthcare $(58 / 45.7 \%)$ areas, with only three studies $(2.3 \%)$ developed in the professional area.

The classification of studies according to the research areas is shown in Table 1.

Table 1 - Distribution of course completion studies of the programs of professional master's degree in Nursing by research areas, Brazil, 2006 to 2012

\begin{tabular}{lcc}
\hline \multicolumn{1}{c}{ Research areas } & $\mathbf{n}$ & $\%$ \\
\hline Care process & 25 & 19.7 \\
Management & 23 & 18.1 \\
Education & 16 & 12.6 \\
Adults' health & 16 & 12.6 \\
Workers' health & 14 & 11.0 \\
Healthcare policies and practices and & 13 & 10.2 \\
professional nursing activity & & \\
Children's health & 7 & 5.5 \\
Women's health & 5 & 3.9 \\
Family care & 4 & 3.2 \\
The elderly's health & 2 & 1.6 \\
Ethics & 1 & 0.8 \\
Systematization of the Nursing care & 1 & 0.8 \\
Total & 127 & 100.0 \\
\hline
\end{tabular}

When analyzing the methods adopted in the design of the course completion studies, the predominance of qualitative studies can be noted, as per Figure 2.

Most qualitative studies do not specify the type of approach used, being possible to identify nine 
studies that used Phenomenology, seven that used the convergent healthcare research, three that used the Grounded Theory, two Ethnography ones and one of Socio Poetics. There is also little detail concerning the method in the quantitative studies and two quasi-experimental studies, one clinical longitudinal randomized and one intersectional survey were identified.

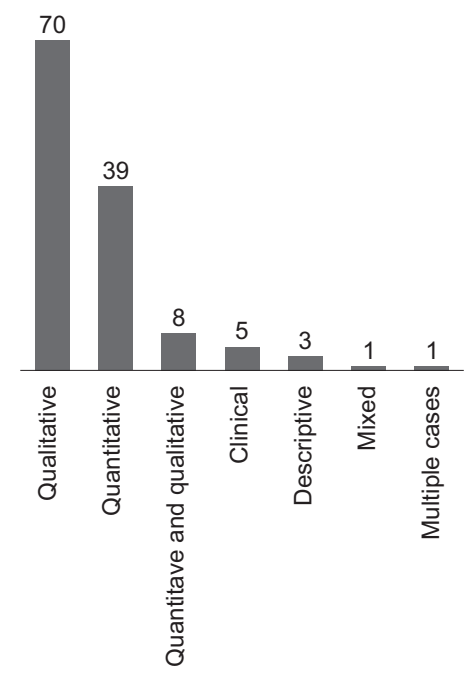

Figure 2 - Methods employed (absolute number) in the course completion studies of the programs of professional master's degree in Nursing, Brazil, 2006 to 2012

The analysis of the verbs found in the objectives of the dissertations points out that most of the studies $(110 / 86.6 \%)$ consisted of an investigation aimed at understanding (27), evaluating (22), analyzing (13), knowing (eight), characterizing (five), describing (five), learning (four), comparing (two), listing (two), investigating (one), recognizing (one), discussing (one), mapping (one), quantifying (one) and delineating (one). In another 17 (13.4\%) studies, propositional verbs were found, such as: construct (four), prepare (three), propose (three), administer (two), develop (one), undertake (one), implement (one), test (one) and create (one), with some recommendations in the end suggesting changes in the practice, but few of them present any in relation to results and processes.

The results of the course completion studies were various and characterized as: services evaluation and healthcare programs (14), preparation of healthcare protocol or directed to education (12), implementation of nursing care systematization (five), educational booklets (three), proposition of initiatives for continuous education (three), development of instrument collection of clinical data in hospitals or primary care (two), instrument for measuring workload (one), development of manual covering nursing procedures (one), implementation of service or program (one), development of occupational risk map (one) and development of a recreational CD (one).

Although they are an important result, the developed processes are more difficult to analyze, given that they are often related to aspects not always expressed in the course completion studies. The following were identified through the reading: the adoption of preventive and health promotion measures by the nursing professionals; the qualification of care, with implementation of protocols and reorganization of work processes, both in hospitals or primary care; the support to healthcare management; the implementation of initiatives for continuous education and participative management; amongst others.

\section{Discussion}

There are only a few studies that analyze the intrinsic aspects of the post-graduation in Nursing. A recent study ${ }^{(12)}$ evaluated the workload of the academic master's degree programs but did not report anything about this aspect in relation to the professional master's degree, since it was not the focus of the study.

The data show a convergence between what has been produced in the programs of professional master's degree in Nursing and the legislation, which is understandable taking into account what the object of study in these programs is, that is, the search for answers to the problems related to the professional practice, not only in the sense of investigating it, but also changing it.

However, the challenge to refine the process of identity construction of the professional master's degree in Brazil remains. Proximity to the perspective of the academic master's degree is observed when the adoption of verbs that lead to objectives of investigations, as well as the adopted methodological drawings, is analyzed. There is creation of knowledge based on the practice, but most of the studies are restricted to investigative actions that do not result in immediate changes, although they produce results that lead to further interventions. When the results and processes are identified, they are also shown to be focused on the improvement of care, providing tools to the healthcare staff, in particular the Nursing team.

These aspects can be understood by analyzing the history of the implementation of professional master's degrees in Nursing. Since the first programs, the 
evaluation process did not point out to clear differences between one level of graduation and the other and this aspect was seen until the triennium 2007-2009. This process limited the reach of the professional master's degree concerning the production of studies that allowed direct interventions in the practice.

The research areas/activities identified meet the objectives of the professional master's degree, that is, there is a concern about the professional practice and the dimensions of the Nursing work process, which are based on the care, the management and education, where the care and management dimensions stand out ${ }^{(13-14)}$.

It is necessary to consider that there is currently a concern with the certification of the healthcare institutions, and the protocols, standards and procedures that guide the care are essential. The processes that result from the analyzed programs are shown to contribute to the change of the professional practice, with emphasis on the reorganization of work processes and the qualification of care and management of health and nursing.

Despite the range of possible formats for the course completion studies, every analyzed work was in the form of dissertation. However, not all these works were bibliographic, which shows the importance of developing alternative forms of dissemination, besides the journals.

This characteristic of the professional master's degree reinforces its differences from the academic master's degree, since it allows the development of new studies and services, especially when considering that the National Policy on Science, Technology and Healthcare Innovation states that the Healthcare Research field is composed of knowledge, technology and innovation of which application results in improvements in the population's health ${ }^{(15)}$. This aspect is also shown in the Master's Degree Courses from other countries, where professional graduation is focused on improvement of care, use of practice based on evidence and innovation ${ }^{(16-18)}$.

The results of the programs also show, even incipiently, that the professional master's degree has the potential to strengthen the results focused on the improvement of care and the relationships between professionals and clients. These results lead to the use of light and light-hard technologies when considering the processes, especially those focused on the organization, but are still insignificant in relation to hard technologies(19), such as the development of technological products. The analyzed results are related to the vocation of the Professional Nursing Activity, which is focused on the care, the management and the education and is little concerned with the creation of patentable products.

Concerning the perspectives of the professional master's degree programs, it is important to mention that the National Policy on Science, Technology and Healthcare Innovation points out that the creation of this education level is required to qualify technicians from the healthcare services network of the Unified Health System - SUS. This initiative is aimed at improving the qualification and skills in order to develop researches that will lead to the improvement of the professional practice and the quality of care ${ }^{(15)}$.

Despite taking the above indication into account, a study that analyzed the characteristics of the graduates from the professional master's degree programs in the area of healthcare science and technology management showed that, although there is "evidence of possible changes in the services where the graduates worked", difficulties were encountered in the healthcare institutions in relation to the incorporation of innovative proposals, especially those related to institutional management(20).

In this sense, it is essential that programs are articulated with the healthcare institutions, because there is no chance of promoting changes without their involvement. It is not sufficient for the projects developed in the programs to be relevant, but they will only have an impact with the consent and support of institutions for them to occur effectively. The institutional partnership and commitment can ensure that they are implemented and consolidated.

The programs of professional master's degree in Nursing are in the process of construction, especially when compared to the academic master's degrees, since there is a 30- year-gap between these two types of stricto sensu post-graduation ${ }^{(21-23)}$. The former were created in the early 2000s, while the latter were created in the 1970s. Therefore, the consolidation of the professional master's degree programs is a challenge to be overcome (20-23). $^{2}$

\section{Final considerations}

The results of this study show that the programs of professional master's degree in Nursing are going through a consolidation stage. The studies are recent and still being developed, especially because they have to focus on the development of products that cause an impact on the professional practice, which has 
occurred only when light and light-hard technologies are considered, taking into account that the production of hard technologies are still inexistent. In this sense, the gap in the technological production and innovation is highlighted and this is a field to be developed.

Despite these gaps, the programs of professional master's degree in Nursing have sought to introduce technological innovations and new forms of work organization, which have become essential for the development of professional practices, since they redesign the articulations between the healthcare and the educational sectors, developing abilities and skills that encourage innovative practices.

This constitutes a potential for the professional master's degrees and, although the programs have already been focused to qualify professionals who are engaged in the healthcare services, there is room to increase the insertion of professionals working in public healthcare services. This situation points out to the area in which the Professional Nursing Activity needs to act on in the next triennium.

The fact that the production analyzed has great similarity with that of the academic master's degree shows the required steps to be taken in order to improve the projects of the professionals master's degree programs, especially showing that it is essential to seek the identity of this level of education in the area, as well as the graduation process, with the purpose of supporting products that change the practice.

As for the products created, there was scientific accuracy in the studies that develop them, showing the commitment with knowledge production. The predominant methodological framework is the qualitative one, which allows intervention besides the investigation. However, this is an aspect that needs to be improved, since the objective of the studies showed more investigation than intervention, and there is also a need to consider the relevance of clinical and epidemiological studies for practice improvement.

This preliminary analysis indicates a path to be built, which should be based on national policies that allow the production of professional master's degree, with development of technologies related to care/ healthcare practice, allowing an evidence-based professional practice.

It can also be noted the need to deepen the discussion in the Professional Nursing Activity area about the importance to develop and register patents. The results point out to a gap in this issue, although the organizational field has stood out in the analyzed studies.
The analysis of the results of the study shows some challenges for the area. Concerning the objectives and evaluation of the existing professional master's degree programs, their consolidation and support are essential in the pursuit of national excellence, reaching grade 5 in the evaluation; to enhance this type of course with special attention to professional education in the area the program is focused on, to the development of critical thinking and the creation of technology and methods of research; to improve the evaluation process with effective participation of researchers with extensive experience in these programs, in the commissions of area consultant, and in the review of evaluation criteria, with addition of new indicators of technological productivity and social development.

As for the final results of the programs, it is necessary to provide knowledge and technology that have an impact on better and more effective ways of protecting and promoting health with quality of life and reducing disease, in the search for answers and solutions to the health problems of the population related to the healthcare management and the education of Nursing staff; to turn scientific knowledge into innovative products and processes to meet the needs of professional practice and the new demands of the society; to articulate the objects of study to the needs of the services, to the priorities in health research and to the National Policy on Science, Technology and Healthcare Innovation; to enhance the development of studies and processes with the purpose of implementing an evidence based practice, reducing the gap between knowledge and clinical practice and contributing to the development of the best practices and the consolidation of the SUS.

In relation to funding, there are also challenges, which are: to increase funding uptake in the public and private sectors in order to ensure the sustainability of these programs, with scholarships for the students of master's degrees and technological development for the researchers, financial resources for the proposed scientific and technological as well as innovative projects. There is also the need to consider the implementation, among the professional master's degree programs, of cooperative networks and research, technological and innovative environments in the area of Nursing and healthcare with the goal of providing a safe and high quality care.

\section{References}

1. Parecer no 977/65, C.E.Su, aprovado em 03 de dezembro de 1965 (BR). Definição dos cursos de 
pós-graduação. 1965. [acesso 5 mar 2013]. Disponível em: http://www.capes.gov.br/images/stories/download/ legislacao/Parecer_CESU_977_1965.pdf

2. Portaria n 80, de 16 de dezembro de 1998 (BR). Dispõe sobre o reconhecimento dos mestrados profissionais e dá outras providências. Diário Oficial da União [Internet]. 11 jan 1999. [acesso 5 mar 2013]. Disponível em: http://www.capes.gov.br/images/stories/download/ legislacao/Portaria_CAPES_080_1998.pdf

3. Portaria normativa no 17, de 28 de dezembro de 2009 (BR). Dispõe sobre o mestrado profissional no âmbito da Fundação Coordenação de Aperfeiçoamento de Pessoal de Nível Superior - CAPES. Diário Oficial da União [Internet]. $29 \mathrm{dez}$ 2009. [acesso 5 mar 2013]. Disponível em: http://www.capes.gov.br/images/stories/download/ legislacao/PortariaNormativa_17MP.pdf

4. MEC. CAPES (BR). Plano Nacional de Pós-graduação - PNPG - 2011- 2020/CAPES. - Brasília: CAPES; 2010. v. 1,309 p.

5. Barros EC, Valentim MC, Melo MAA. O debate sobre o mestrado profissional na Capes: trajetória e definições. RBPG. 2005;2:124-38.

6. Ribeiro RJ. O mestrado profissional na política atual da CAPES. RBPG. 2005;2(4):8-15.

7. Oller C, Sotero A, Moreira MA, Ficher T. Parâmetros para avaliação de mestrado profissional. RBPG. 2005;2:151-5.

8. Enfermagem [Internet]. Brasília: CAPES; 2006. [acesso 6 mar 2013]. Disponível em: http://www.capes. gov.br/component/content/article/44-avaliacao/4667enfermagem

9. Gil AC. Métodos e técnicas em pesquisa social. São Paulo: Atlas; 2008.

10. Associação Brasileira de Enfermagem. Consolidação das propostas de linhas de pesquisa em enfermagem. 2001. [acesso 6 mar 2013]. Disponível em: http://www. abennacional.org.br/index.php?path $=195$.

11. Munari DB, Chaves LDP, Peduzzi M, Laus AM, Fugulin FMT, Ribeiro LCM, Scochi CGS. The setting of research production by nursing and management graduate programs in Brazil. Rev EsC Enferm USP. 2011;45(spe):1543-50.

12. Robazzi MLCC, Erdmann AL, Fernandes JD, Rodrigues RAP, Lunardi VL. Cursos de mestrado acadêmico na área de enfermagem: análise da carga horária. Rev. LatinoAm. Enfermagem. 2012;20:1152-60.

13. Leopardi MT, Gelbcke F, Ramos F. Cuidado: objeto de trabalho ou objeto epistemológico da enfermagem? Texto Contexto-Enferm. 2001;10:32-49.
14. Azzolin GMC, Peduzzi M. Processo de trabalho gerencial e processo de enfermagem na perspectiva de docentes de enfermagem. Rev Gaúcha Enferm. 2007;28:549-55.

15. Ministério da Saúde (BR). Política Nacional de Ciência, Tecnologia e Inovação em Saúde. $2^{a}$ ed. Brasília: Ministério da Saúde; 2008. 44 p.

16. Watkins D. The influence of Masters education on the professional lives of British and German nurses and the further professionalization of nursing. J Adv Nurs. 2011;67:2605-14.

17. Watkins D. Motivation and expectations of German and British nurses embarking on a masters programme. Nurse Educ Today. 2011;31:31-5.

18. Whyte DA, Lugton J, Fawcett TN. Fit for purpose: the relevance of Masters preparation for the professional practice of nursing. A 10-year follow-up study of postgraduate nursing courses in the University of Edinburgh. J Adv Nurs. 2000;31:1072-80.

19. Merhy EE. Saúde: a cartografia do trabalho vivo. $2^{a}$ ed. São Paulo: Hucitec; 2005.

20. Hortale VA, Leal MC, Moreira COF, Aguiar AC. Características e limites do mestrado profissional na área da Saúde: estudo com egressos da Fundação Oswaldo Cruz. Ciênc Saúde Coletiva. 2010;15(4):2051-8.

21. Scochi CGS, Munari DB. A pós-graduação em Enfermagem brasileira faz quarenta anos: avanços, desafios e necessidades de novos empreendimentos. Esc Anna Nery. 2012;16:215-8.

22. Tavares CMM, Leite MMJ. Reflexões sobre 0 mestrado profissional em enfermagem. Rev Pesqui Cuidado é Fundamental Online [Internet]. 2011. [acesso 20 fev 2013];3(1). Disponível em: http://www. seer.unirio.br/index.php/cuidadofundamental/article/ viewFile/1373/pdf_376

23. Saupe $R$, Wendhausen ALP. O mestrado profissionalizante como modelo preferencial para capacitação em Saúde da Família. Interface. 2005; 9:621-30. 